\title{
COLONIZAÇÃO MICORRÍZICA EM PLANTIOS DE EUCALIPTO ${ }^{1}$
}

\author{
Daniela Tiago da Silva Campos², Marliane de Cássia Soares da Silva³, José Maria Rodrigues da Luz³, \\ Rosenval Junior Telesfora ${ }^{4}$ e Maria Catarina Megumi Kasuya ${ }^{5}$
}

\begin{abstract}
RESUMO - A associação micorrízica é advinda da associação simbiótica entre alguns fungos do solos e da maioria das raízes das plantas. O eucalipto possui a capacidade de se associar com dois tipos de micorrizas, a micorriza arbuscular e a ectomicorriza, o que depende muito da sua idade. Este trabalho objetivou avaliar a taxa de colonização por fungos micorrízicos arbusculares (MA) e ectomicorrízicos (ECM) e o número de esporos de fungos micorrízicos arbusculares em plantios comerciais de Eucalyptus grandis e Eucalyptus urophylla, com diferentes idades e manejos, no período de dezembro de 2002 a fevereiro de 2004, na região leste de Minas Gerais, Brasil. Em todas as coletas e em todas as idades dos plantios, foram encontradas MA, e ECM e a média geral da colonização por fungos micorrízicos arbusculares (FMA) foi de 26\%. O número médio de esporos desses fungos de 374,7 por 100 g de solo e a colonização por fungos ectomicorrízicos (FECM) de 20,2\%. As maiores porcentagens de colonização por FECM foram observadas em áreas de plantios mais jovens, mas a sua maior diversidade foi observada nas áreas de plantios mais velhos. Conclui-se que a época de coleta, a idade do plantio e o manejo do solo afetam a colonização micorrízica e também a diversidade de fungos ECM e que a sucessão de eucalipto com FMA-FECM não é regra e é muito influenciada pelo tipo de manejo.

Palavras-chave: Eucalyptus spp., Micorriza arbuscular e Ectomicorriza.
\end{abstract}

\section{MYCORRHIZAL COLONIZATIONS IN EUCALYPT PLANTATIONS}

\begin{abstract}
Mycorrhyzal association is the symbiotic association among some soil fungus and most plant roots. Eucalyptus has the capacity of associating with two types of mychorrizal, arbuscular and ectomycorrhizal mycorrhizal,depending of its age. The objective of this work was to evaluate colonization rates by arbuscular mycorrhizal fungi (AM) and ectomycorrhizal fungi (ECM) and the number of spores of arbuscular mycorrhizal fungi in in commercial plantations of Eucalyptus grandis and Eucalyptus urophylla, at different ages and managements practices, from December 2002 to February, 2004, in eastern region of Minas Gerais, Brazil. In all periods of sampling and at all ages of the plant, it was found both AM and ECM and the colonization general mean by arbuscular mycorrhizal fungi (AMF) was $26 \%$. The average number of spores of those fungi was 374.7 per $100 \mathrm{~g}$ of soil and colonization by ectomycorrhizal fungi (EMF) was $20.2 \%$. Most percentages of colonization by EMF were observed in areas with younger plantations, but it greatest diversity was observed in older plantation areas. It can be concluded that sampling period, age of the plantation and soil management practices affect mycorrhizal colonization and also ECM fungi diversity and succession of eucalyptus with AMECM is not a rule and it is strongly affected by management.
\end{abstract}

Key words: Eucalyptus spp., Arbuscular mycorrhiza and Ectomycorrhiza.

\section{INTRODUÇÃO}

O Brasil demanda cerca de 350 milhões de $\mathrm{m}^{3} \mathrm{ano}^{-1}$ de madeira, o que significa $8 \%$ do consumo mundial. No país, há 2,9 milhões de hectares de florestas plantadas predominantemente com Eucalyptus grandis, que ocupa 55\% da área total, seguida de 17\% com Eucalyptus saligna, 9\% com Eucalyptus urophylla, 2\% com E. viminalis, 11\% com híbridos de E. grandis x E. urophylla,

\footnotetext{
${ }^{1}$ Recebido em 02.03.2009 e aceito para publicação em 02.05.2011.

${ }^{2}$ Departamento de Fitotecnia e Fitossanidade, Universidade Federal de Mato Grosso, UFMT, Brasil. E-mail: <camposdts@yahoo.com.br>.

${ }^{3}$ Programa de Pós-Graduação em Microbiologia Agrícola pela Universidade Federal de Viçosa, UFV, Brasil. E-mail:

<mcassiabio@yahoo.com.br>e <josemarodrigues@yahoo.com.br>.

${ }^{4}$ Graduado em Engenharia Florestal. E-mail: <rosenvalcosta@yahoo.com.br>.

${ }^{5}$ Departamento de Microbiologia, Universidade Federal de Viçosa, UFV, Brasil. E-mail: <mkasuya@ufv.br>.
} 
e 6\% com outras espécies. A maioria dos plantios está localizada nas regiões sul e sudeste do país. No estado de Minas Gerais, a área plantada é de 1.535.290 ha (SBS, 2009).

O grande sucesso desses plantios é resultado da boa adaptabilidade do eucalipto em solos com limitada quantidade de fósforo e nitrogênio (BRAGA et al., 1995; SPECHT, 1996) e da formação, em seu sistema radicular, da ectomicorriza (ECM) e da micorriza arbuscular (MA) (YINGLONG et al., 1999). A associação micorrízica propicia maior longevidade às raízes, incrementa a absorção de água e de nutrientes do solo, mobiliza formas não disponíveis de nutrientes (MARCHNER; DELL, 1994; MORATELLI et al., 2007), maior resistência a patógenos do sistema radicular, maior tolerância a toxinas do solo e a condições adversas de $\mathrm{pH}$ e de temperatura (SMITH; READ, 1997).

Levantamentos realizados em florestas de Eucalyptus têm levado à constatação de que a idade da planta tem influência sobre o tipo de associação micorrízica predominante e, consequentemente, sobre a diversidade de micorrizas formadas. Inicialmente, há colonização por fungos micorrízicos arbusculares (FMA), substituída progressivamente pelas associações por fungos ectomicorrízicos (FECM) com o avanço da idade (BELLEI et al., 1992; YINGLONG et al., 1999; SANTOS et al., 2001). A colonização por fungos micorrízicos pode ser influenciada também pela espécie de eucalipto. A inoculação concomitante dos dois tipos de fungos micorrízicos pode, inclusive, levar à competição e reduzir a colonização (YINGLONG et al., 1999).

A época da coleta para a avaliação da colonização micorrízica pode influenciar no resultado. Em três regiões de Minas Gerais, verificou-se que, no período seco, a colonização por FMA foi três vezes maior do que no período chuvoso. Já o número de esporos de FMA no solo foi maior no período chuvoso, e a percentagem de colonização por FECM não apresentou modelo definido com a época de amostragem (COELHO et al., 1997).

Em plantios comerciais de eucalipto no Brasil, pouco se conhece sobre a colonização micorrízica, mas em outras espécies vegetais já há alguns trabalhos (MORATELLI et al., 2007; SILVA et al., 2008; CAPRONI et al., 2005) em que foi observada a densidade de esporos de Glomus clarum e Gigaspora margarita em plantio de mudas de Acácia mangium em estéril revegetado.
Os autores constataram que a densidade foi elevada e aumentou com a idade, enquanto o número de espécies não variou e a maioria das espécies de FMAs não apresentou o mesmo padrão de esporulação nos períodos seco e chuvoso.

Este trabalho teve como objetivo determinar as colonizações micorrízicas por FECM e FMA e o número de esporos de FMA em plantios de eucalipto com idade entre 6 e 180 meses, em diferentes épocas do ano e diferentes tipos de manejos.

\section{MATERIAL E MÉTODOS}

\subsection{Localização e caracterização geral da área de estudo}

O trabalho foi realizado com solos coletados em plantios comerciais de eucalipto pertencentes à empresa CENIBRA Celulose Nipo-Brasileira S.A., com idades variando entre 6 e 180 meses, localizados na região leste do Estado de Minas Gerais. O clima da região, segundo a classificação de Köppen, é do tipo Aw, tropical chuvoso, clima de savana, com chuvas no verão e com inverno seco (VIANELLO; ALVES, 1991).

No início de suas atividades, a empresa utilizava a queimada para a limpeza das áreas, tanto nas novas quanto nas de replantio. Porém, observou-se que esta técnica não era viável em longo prazo, pois estava levando a uma redução acelerada da qualidade do solo. Assim, o cultivo mínimo foi implantado em todas as áreas.

A empresa possui grandes áreas de plantio que vêm sendo manejadas sob diferentes formas e, dentre essas áreas, fez-se a escolha de algumas para este trabalho. A caracterização completa das áreas escolhidas, os manejos empregados e a caracterização química das áreas encontram-se detalhados nas Tabelas 1, 2 e 3, respectivamente.

No início de suas atividades, a empresa utilizava a queimada para a limpeza das áreas, tanto nas novas quanto nas de replantio. Porém, observou-se que esta técnica não era viável em longo prazo, pois estava levando a uma redução acelerada da qualidade do solo. Assim, o cultivo mínimo foi implantado em todas as áreas.

\subsection{Locais de coleta e amostragem de solo e de raiz}

As coletas foram realizadas durante os meses de dezembro de 2002, fevereiro, maio, agosto e novembro de 2003 e fevereiro de 2004. As precipitações 
pluviométricas para as épocas de coleta foram de 310, 20, 17, 20, 30 e $250 \mathrm{~mm}$, respectivamente. As temperaturas nas épocas de coleta foram de $26,26,19,19,24,23^{\circ} \mathrm{C}$, respectivamente.

A escolha de árvore de cada área foi feita de forma aleatória dentro de um talhão de 1 ha. Em cada coleta, foram amostradas 3 árvores, sendo feitas duas amostras simples a uma distância de $1 \mathrm{~m}$ do tronco da planta, em lados opostos. As amostragens de solo e de raízes foram realizadas na profundidade de 0 a $20 \mathrm{~cm}$, após a retirada da serrapilheira, de galhos ou troncos caídos no local. A coleta do solo foi realizada com uma pá, - cerca de 500 g de solo por amostra simples. Essa amostra foi passada por peneira de $2 \mathrm{~mm}$, acondicionada em saco plástico, mantida em local fresco e protegida do sol. Posteriormente, foi levada para o laboratório, onde foi mantida a $4{ }^{\circ} \mathrm{C}$ até o processamento.

As raízes foram coletadas de forma aleatória, no mesmo local em que o solo foi retirado, seccionadas em tamanhos de 4 a $6 \mathrm{~cm}$ e armazenadas em frascos de vidro contendo FAA (formaldeído 100\% : etanol 70\% : ácido acético 100\% = 5:90:5), para posterior avaliação da colonização por FMA e FECM (BRUNDRETT et al., 1996).

\subsection{Avaliação da colonização micorrízica}

Para a avaliação da colonização micorrízica, as amostras do sistema radicular foram lavadas em água corrente e cortadas em fragmentos de 1 a $2 \mathrm{~cm}$ de comprimento. A descoloração e a coloração destes fragmentos foram realizadas utilizando-se a técnica descrita por Koske e Gemma (1989). A percentagem do comprimento de raiz colonizada por FMA e FECM foi avaliada pelo método de interseção em placa quadriculada, sob lupa binocular com aumento de 40 vezes (GIOVANNETTI; MOSSE, 1980). Os segmentos que apresentavam vesículas, arbúsculos ou hifas características, por vezes ligadas a esporos típicos, foram considerados colonizados por FMA, enquanto os que apresentavam manto fúngico, colonizados por FECM. Os esporos de FMA foram extraídos de 100 g de solo pela técnica de decantação e peneiramento úmido (GERDEMANN; NILCOLSON, 1963).

\subsection{Forma de análise dos resultados}

Os resultados obtidos foram submetidos à análise de variância e as médias comparadas pelo teste de Tukey, a 5\% de probabilidade. Realizou-se também uma análise de componentes principais (PCA) utilizando distância euclidiana e transformação logarítmica dos dados (log $(\mathrm{X}+1)$ ) pelo programa CANOCO versão 4.5 (MCCUNE ;MEFFORD, 1999).

\section{RESULTADOS E DISCUSSÃO}

Os resultados de colonização micorrízica das raízes de Eucaliptus grandis e Eucaliptus urophulla nos diferentes manejos e épocas de amostragem encontram-se nas Figuras 1, 2 e 3. Observou-se que, em todas as áreas e épocas de coleta, foram encontradas raízes colonizadas e esporos de FMA. A colonização por FECM variou de 4 a 42,3\%, a de FMA variou de 3,4 a $62,1 \%$, enquanto o número de esporos de FMA variou de 61 a 1.106 por $100 \mathrm{~g}$ de solo.

As taxas de colonização micorrízica observadas mostraram-se semelhantes às dos estudos realizados na região sul do país (BELLEI et al., 1992) e não houve um predomínio de FMAs em plantios mais jovens e nem de FECMs em plantios mais velhos. A colonização micorrízica é uma característica que pode ser afetada por inúmeros fatores como a espécie vegetal, a idade da planta, a densidade de raízes, dos propágulos fúngicos no solo e do tipo de manejo empregado no solo na hora do plantio, dentre outros. As áreas em que a queimada foi utilizada para o preparo do solo apresentaram as menores taxas de colonização (Figuras 1 e 2), indicando que a queimada não foi o melhor manejo no estabelecimento da associação micorrízica.

A idade das plantas amostradas não foi um diferencial na colonização micorrízica, não permitindo ser observado um padrão de distribuição nos plantios com as diferentes idades. Porém, Caproni e colaboradores (2005) observaram que o número de esporos de FMAs aumentou com a idade das plantas de Acacia mangium em áreas de mineração de bauxita. Já Cordeiro e colaboradores (2005) observaram um pequeno efeito positivo dos sistemas de manejo na colonização micorrízica e no número de esporos de FMAs em detrimento das áreas de referência; as áreas sob o cultivo de gramíneas apresentaram maior colonização micorrízica e densidade de esporos de FMA.

Na primeira avaliação, realizada em dezembro de 2002, a colonização por FECM e por FMA no plantio mais jovem foi de $21,7 \%$ e $50,8 \%$, respectivamente; e no plantio mais velho de $12,8 \%$ e $57 \%$,

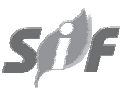

Revista Árvore, Viçosa-MG, v.35, n.5, p.965-974, 2011 

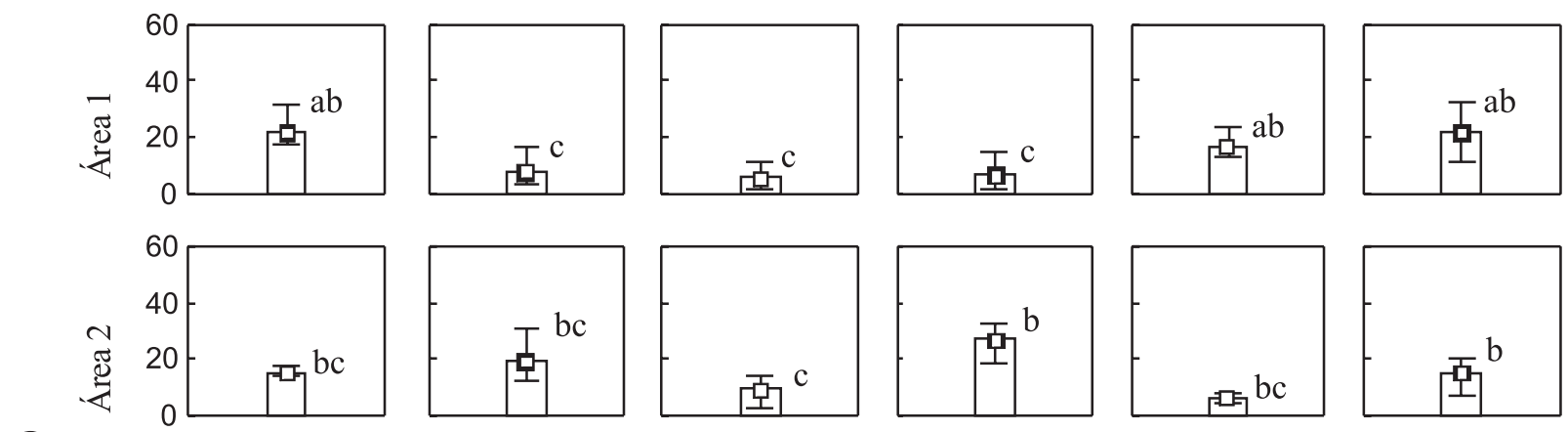

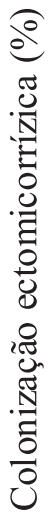
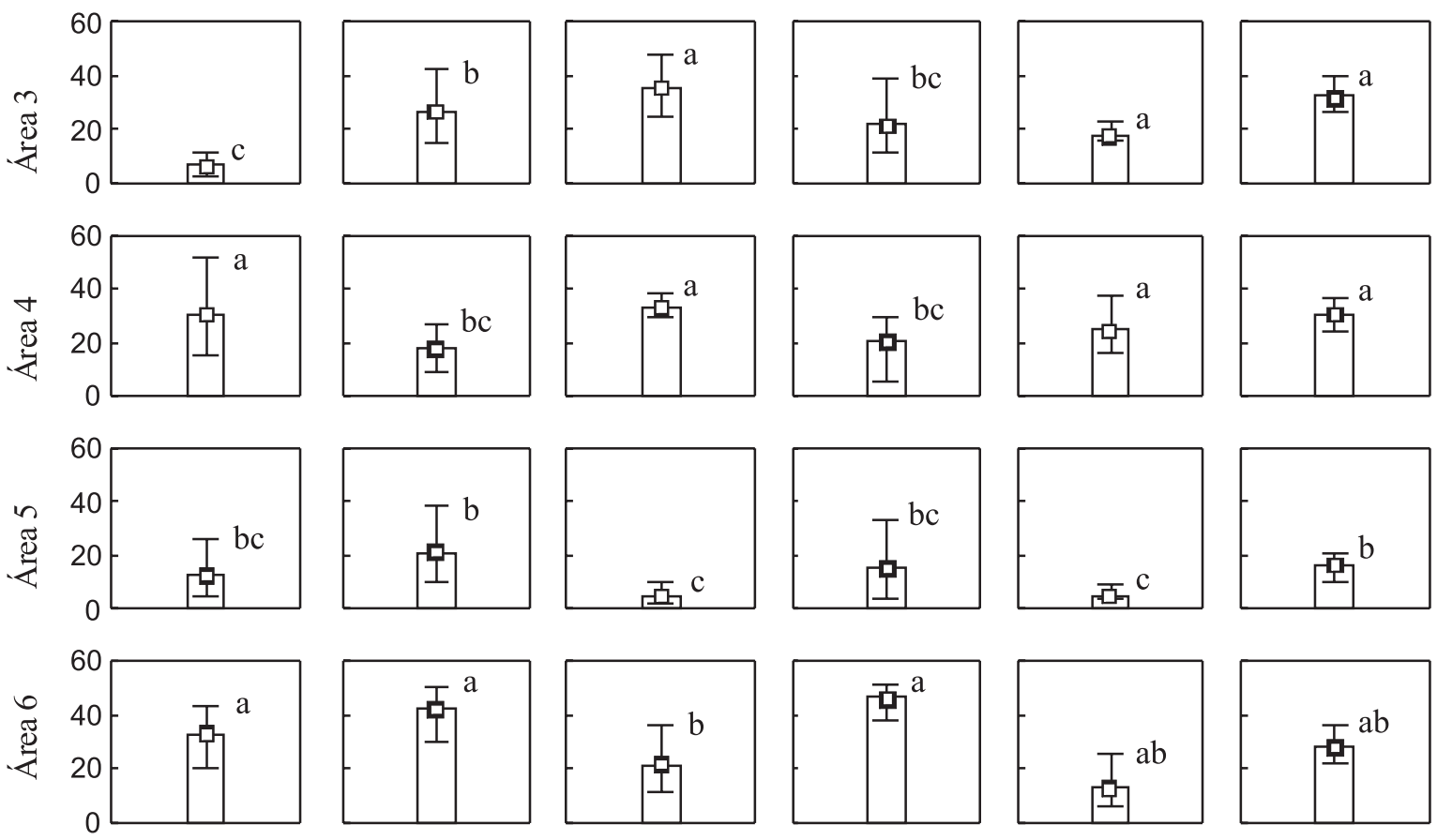

Fev-2003

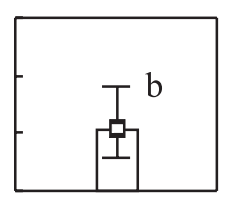

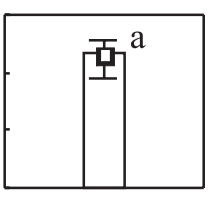

Ago-2003

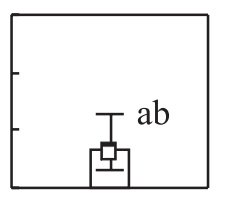

Nov-2003

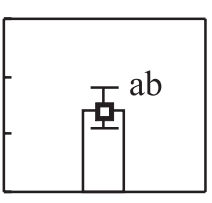

Fev-2004

Figura 1 - Colonização micorrízica por FECM de plantas de Eucalyptus grandis e Eucalyptus urophylla, em áreas com diferentes idades e manejos, em diferentes épocas de amostragem. Médias seguidas pelas mesmas letras nas colunas não diferem entre si a 5 \% de significância pelo teste de Tukey.

Figure 1 - Mycorrhizal colonization by ECM of Eucalyptus grandis and Eucalyptus urophylla, at different ages and managements, at different times of sampling. Averages followed for the same letters in the columns do not differ from each other at $5 \%$ of significance by the Tukey test.

respectivamente (Figuras 1 e 2). E esperava-se maior colonização por FMA em plantios mais jovens e de FECM em plantios mais velhos. Também não foi possível observar a sucessão micorrízica já relatada em alguns trabalhos, como no de Bellei et al. (1992), que avaliaram a sucessão micorrízica em plantios jovens de Eucalyptus viminalis, em Santa Catarina, sul do Brasil. Yinglong et al. (1999), na China, avaliaram a sucessão micorrízica em Eucalyptus urophylla em casa de vegetação, ocorrendo o predomínio de FMA em plantas mais jovens e de FECM em plantas mais velhas. 

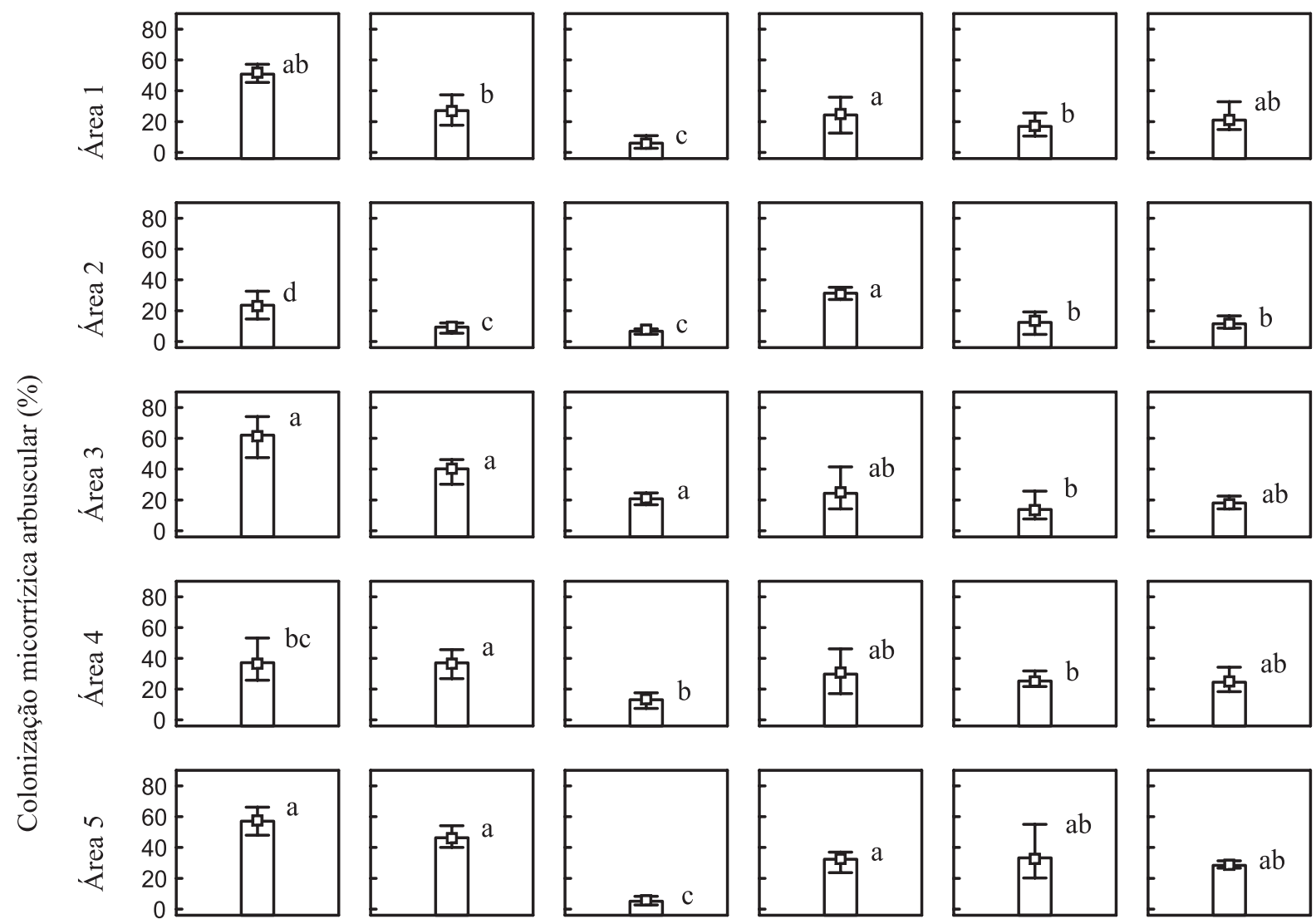

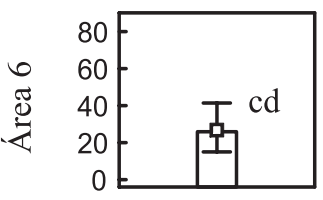

Dez-2002

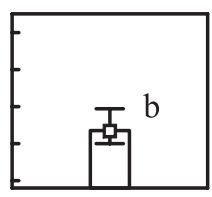

Fev-2003

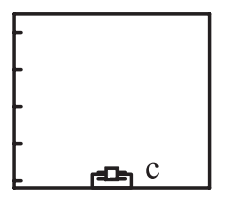

Mai-2003

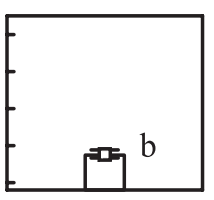

Ago-2003

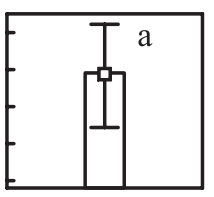

Nov-2003

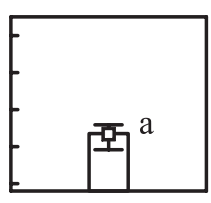

Fev-2004

Figura 2 - Colonização micorrízica por FMA de plantas de Eucalyptus grandis e Eucalyptus urophylla, em áreas com diferentes idades e manejos, em diferentes épocas de amostragem. Médias seguidas pelas mesmas letras nas colunas não diferem entre si a 5 \% de significância pelo teste de Tukey.

Figure 2 - Mycorrhizal colonization by FMA of Eucalyptus grandis and Eucalyptus urophylla, at different ages and managements, at different times of sampling. Averages followed by the same letters in the columns do not differ from each other at $5 \%$ of significance level by the Tukey test.

Smith e Read (1997) relatam que em plantios de eucalipto há uma sucessão micorrízica com predomínio de FMA em plantios mais jovens e de FECM em plantios com idades avançadas. Esta sucessão não foi observada nesse trabalho, e isso pode ser explicado pela interferência de vários fatores, dentre eles os bióticos, como a especificidade dos fungos por seus hospedeiros (SMITH; READ, 1997) e os abióticos (SPECHT, 1996;
MORATELLI et al., 2007), como a temperatura e a umidade do solo nos períodos de coleta. Além do mais, nem todos eram do primeiro plantio e receberam também diferentes manejos (Tabelas 1 e 2).

A análise de componentes principais (Figura 4) mostra que a queimada, apesar de ter sido realizada no passado pela empresa como forma de limpeza das 

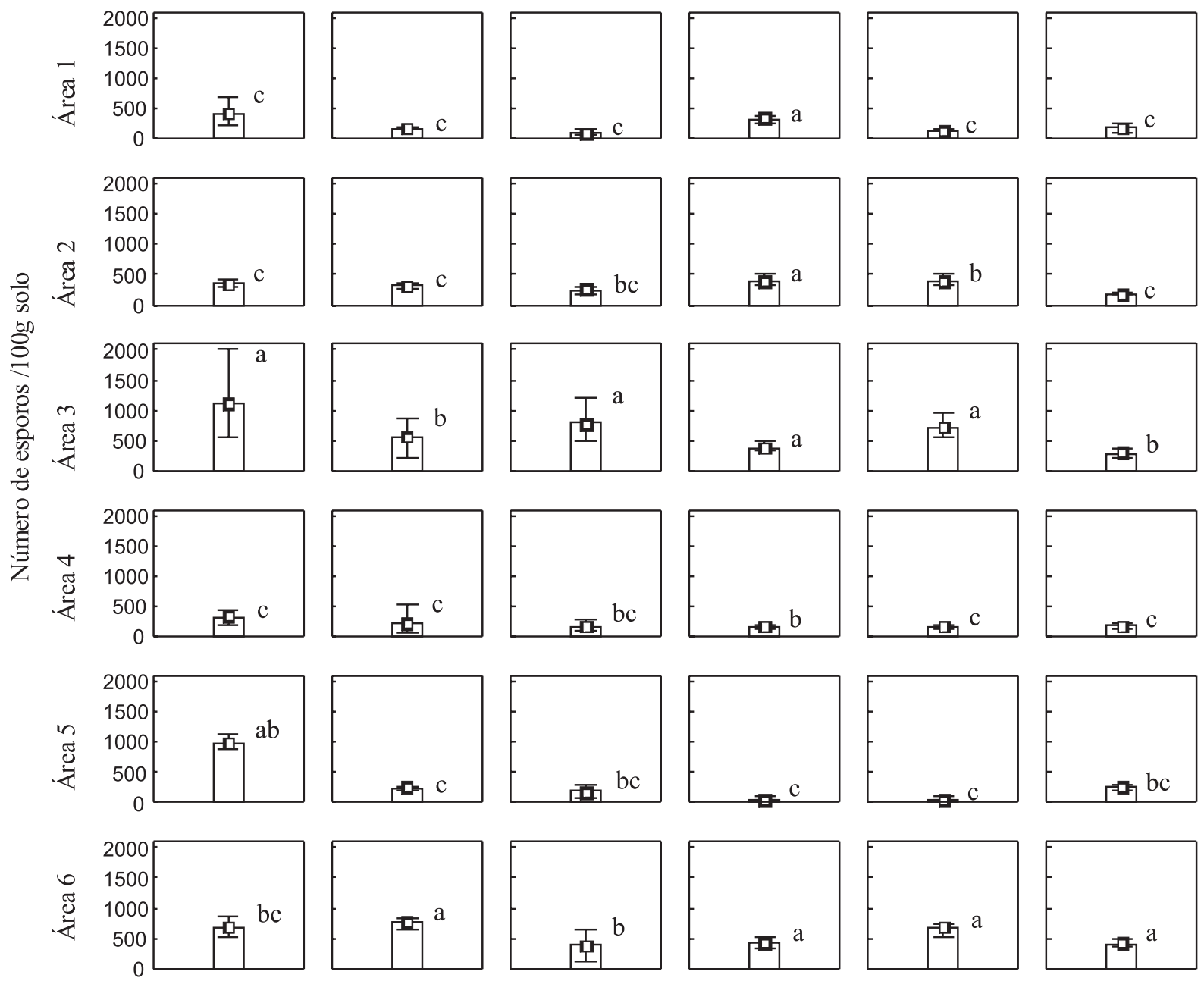

Dez-2002

Fev-2003

Mai2003

Ago-2003

Nov2003

Fev-2004

Figura 3 - úmero de esporos de FMA em plantas de Eucalyptus grandis e Eucalyptus urophylla, em áreas com diferentes idades e manejos, em diferentes épocas de amostragem. Médias seguidas pelas mesmas letras nas colunas não diferem entre si a 5 \% de significância pelo teste de Tukey.

Figure 3 - Number of spores of FMA of Eucalyptus grandis and Eucalyptus urophylla, at different ages and managements, at different times of sampling. Averages followed by the same letters in the columns do not differ from each other at $5 \%$ significance level by Tukey test.

áreas, favoreceu as colonizações por FECM, FMA e o número de esporos. Nas áreas onde foi realizada a queimada, não houve aumento significativo dos teores de matéria orgânica do solo (Tabela 2).

Os fungos micorrízicos em situações de estresse tendem a aumentar os seus propágulos, com a finalidade de perpetuar a espécie, produzindo, assim, maior número de esporos no solo para FMA e de basidiocarpos para FECM (SMITH; READ, 1997). Moreira et al. (2006) estudaram diferentes sistemas de manejo em plantios de araucária e observaram resultados semelhantes aos encontrados neste trabalho, com menor taxa de colonização por FMA para as plantas que estavam em áreas que havia sido queimadas.

Revista Árvore, Viçosa-MG, v.35, n.5, p.965-974, 2011 
Tabela 1 - Identificação das áreas de coleta, abrangendo solos sob eucalipto com diferentes idades e manejos, na região leste de Minas Gerais.

Table 1 - Identificationof sampling areas, covering soil under eucalyptus at different ages and managements, in the eastern region of Minas Gerais.

\begin{tabular}{|c|c|c|c|c|c|c|c|c|}
\hline$\overline{\text { Áreas }}$ & Idade & Espécie & $\begin{array}{l}\text { Coordenadas } \\
\text { Geográficas } \\
\end{array}$ & $\begin{array}{c}\text { Material } \\
\text { genético }^{(2)}\end{array}$ & Manejo & $\begin{array}{l}\text { Tipo de } \\
\text { solo }{ }^{(3)}\end{array}$ & $\begin{array}{l}\text { Altitude } \\
(\mathrm{m})\end{array}$ & Município \\
\hline 1 & 6 meses & E. grandis & 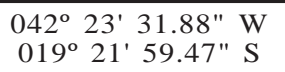 & Clone 2735 & Queimada & CXbd5 & 255 & $\overline{\text { Belo Oriente }}$ \\
\hline 2 & 1 ano & E. grandis & $\begin{array}{c}042^{\circ} 26^{\prime} 59.14 " \mathrm{~W} \\
019^{\circ} 19^{\prime} 48.88^{\prime \prime} \mathrm{S}\end{array}$ & Clone 129 & Queimada & LAd1 & 258 & Belo Oriente \\
\hline 3 & 3 anos & E. grandis & $\begin{array}{lll}042^{\circ} & 24^{\prime} & 9.95^{\prime \prime} \mathrm{W} \\
019^{\circ} & 23^{\prime} & 52.15^{\prime \prime} \mathrm{S}\end{array}$ & Clone 2156 & Cultivo mínimo & LAd1 & 242 & Ipaba \\
\hline 4 & 5 anos & E. grandis & $\begin{array}{c}042^{\circ} 26^{\prime} 34.94 " \mathrm{~W} \\
019^{\circ} 13^{\prime} 7.21^{\prime \prime} \mathrm{S}\end{array}$ & Clone 2750 & Queimada & LAd1 & 223 & Belo Oriente \\
\hline 5 & $15 \operatorname{anos}^{(1)}$ & E. urophylla & $\begin{array}{c}042^{\circ} 22^{\prime} \quad 31.87^{\prime \prime W} \\
019^{\circ} 20^{\prime} 33^{\prime \prime S} \mathrm{~S}\end{array}$ & Semente & Queimada & $\begin{array}{l}\text { Rubd3 } \\
\text { + RUbe }\end{array}$ & 221 & Ipaba \\
\hline 6 & 1 anos & E. grandis & 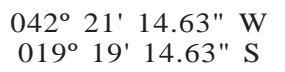 & Clone 129 & Cultivo mínimo & LAd2 & 246 & Iapú \\
\hline
\end{tabular}

${ }^{(1)}$ Pomar de matrizes, contendo híbrido de E. grandis com E. urophylla, usado para obtenção de sementes; ${ }^{(2)}$ A identificação diz respeito ao clone usado naquele talhão. ${ }^{(3)}$ CXbd1: CAMBISSOLO HÁPLICO Tb Distrófico típico, textura muito argilosa ou argilosa, A moderado, álico, caulinítico, hipoférrico ou mesoférrico; CXbd5: CAMBISSOLO HÁPLICO Tb Distrófico latossólico, textura muito argilosa, A moderado, álico, caulinítico, mesoférrico; CXbd14: CAMBISSOLO HÁPLICO Tb Distrófico lítico, textura argilosa, A moderado, álico; LAd1: LATOSSOLO AMARELO Distrófico típico, textura muito argilosa, A moderado, álico, caulinítico, hipoférrico; LAd2: LATOSSOLO AMARELO Distrófico típico, textura argilosa, A proeminente, álico, caulinítico, mesoférrico; LVAw1: LATOSSOLO VERMELHO-AMARELO Ácrico típico, textura muito argilosa, A moderado, álico, gibbsítico-oxídico, mesoférrico; LAw1: LATOSSOLO VERMELHO Ácrico típico, textura muito argilosa, A moderado, álico, caulinítico, caulinítico-oxídico mesoférrico; RUbd3 + RUbe: NEOSSOLO FÚLVICO Tb Eutrófico ou Distrófico típico, textura argilosa/média/arenosa, A proeminente, caulinítico, mesoférrico.

Tabela 2 - Caracterização química das áreas de coleta, abrangendo solos com diferentes idades e manejos, na região leste de Minas Gerais.

Table 2 - Chemical characterization of sampling areas, covering soil under eucalyptus at different ages and managements, in eastern Minas Gerais.

\begin{tabular}{|c|c|c|c|c|c|c|c|c|c|c|c|c|c|c|}
\hline Áreas & $\begin{array}{c}\mathrm{PH} \\
\text { em } \\
\text { Água }^{1}\end{array}$ & $\begin{array}{l}\text { Matéria } \\
\text { Orgânica }\end{array}$ & $\mathrm{P}^{3}$ & $\mathrm{~K}^{4}$ & $\mathrm{Na}^{4}$ & $\mathrm{Ca}^{5}$ & $\mathrm{Mg}^{5}$ & $\mathrm{Al}^{5}$ & $\mathrm{H}+\mathrm{Al}^{6}$ & $\begin{array}{l}\text { Soma } \\
\text { Bases }\end{array}$ & $\begin{array}{c}\text { CTC } \\
\text { efetiva }\end{array}$ & $\begin{array}{c}\text { CTC } \\
\text { total }\end{array}$ & $\begin{array}{c}\text { Sat. } \\
\text { bases }\end{array}$ & $\begin{array}{c}\text { Sat. } \\
\text { de Al }\end{array}$ \\
\hline & $1: 2,5$ & $\mathrm{dag} / \mathrm{dm}^{3}$ & - & $\mathrm{mg} / \mathrm{dm}^{3}$ & ${ }^{3}-$ & & & - - & $\mathrm{cmol}_{\mathrm{c}} / \mathrm{dn}$ & $n^{3}-$ & & - & $-\quad \%$ & - \\
\hline$\overline{1}$ & 6,50 & 2,81 & 10,15 & 28 & 13 & 8,17 & 0,87 & 0,00 & 1,92 & 9,17 & 9,17 & 11,09 & 83 & 0 \\
\hline 2 & 4,20 & 2,71 & 1,82 & 24 & 4 & 0,08 & 0,07 & 0,23 & 11,62 & 0,23 & 0,46 & 11,85 & 2 & 50 \\
\hline 3 & 4,21 & 1,98 & 1,35 & 25 & 2 & 0,36 & 0,11 & 1,65 & 7,70 & 0,54 & 2,19 & 8,24 & 7 & 75 \\
\hline 4 & 4,35 & 2,40 & 2,57 & 22 & 9 & 0,28 & 0,12 & 2,37 & 11,62 & 0,50 & 2,87 & 12,12 & 4 & 82 \\
\hline 5 & 5,18 & 2,57 & 1,03 & 72 & 7 & 2,26 & 0,83 & 0,26 & 3,58 & 3,31 & 3,56 & 6,88 & 48 & 7 \\
\hline 6 & 4,52 & 2,29 & 1,22 & 30 & 3 & 0,31 & 0,23 & 1,47 & 7,96 & 0,63 & 2,10 & 8,59 & 7 & 70 \\
\hline
\end{tabular}

Métodos utilizados pela empresa para a extração dos nutrientes do solo: (1) pH em água pelo Método Potenciométrico; (2) Matéria Orgânica: Método Walkley-Black modificado por diferença de densidade óptica; (3) P: extrator Mehlich; (4) K e Na: fotometria de emissão; (5) Ca e Mg trocável por espectrometria de absorção atômica; (6) Acidez potencial (H+Al) pelo Método Potenciométrico do SMP (Schmacker, Mclean, Pratt).

A maior colonização por FMA foi observada na área com 15 anos de plantio, com plantas de 180 meses e onde a queimada havia sido usada, reservada pela empresa para a coleta de sementes. Essa área apresentava um espaçamento maior entre as árvores e também muitas gramíneas crescendo no sub-bosque, o que pode ter favorecido a multiplicação do FMAs. Segundo Smith e Read (1997), a colonização micorrízica pode ser afetada por vários fatores, como a temperatura e luminosidade. Moratelli et al. (2007) relatam que, em

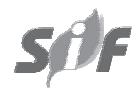

Revista Árvore, Viçosa-MG, v.35, n.5, p.965-974, 2011 


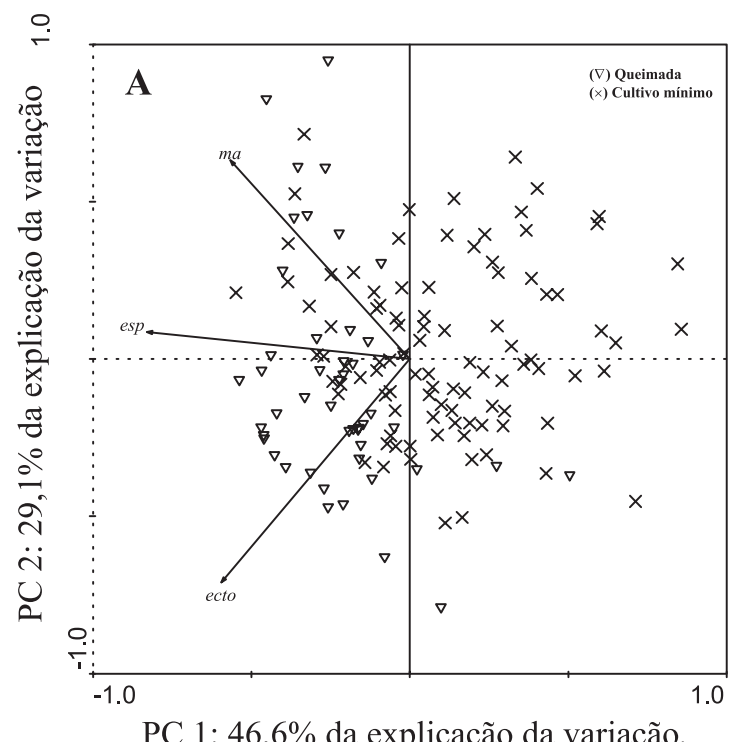

PC 1: 46,6\% da explicação da variação.

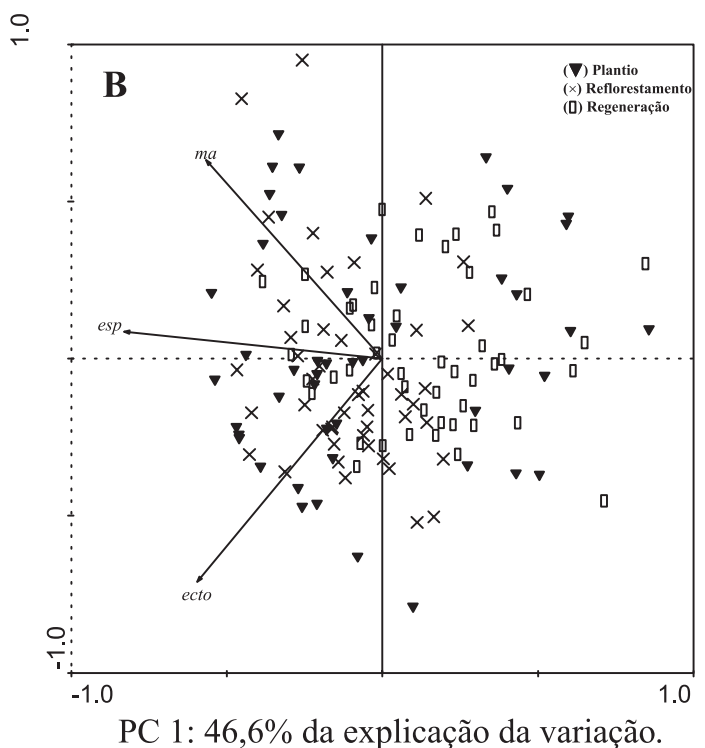

PC 1: 46,6\% da explicação da variação.

Figura 4 - Espaço de Ordenação da Análise de Componentes Principais construída com os dados da colonização micorrízica arbuscular (MA), ectomicorrízica (ECM) e número de esporos de fungos micorrízicos arbusculares (esp). A: manejo utilizado na implantação da cultura, B: forma como o plantio foi realizado. O eixo 1 representa 46,6\% da variabilidade total e o eixo $2,29,1 \%$.

Figure 4-Space of Ordinance of the Analysis of Main Components constructed with the data of the arbuscular mycorrhizal colonization (MA), ectomycorrhizal (ECM) and number of espores of mycorrhizal fungal (esp). A: management used in the implantation of the culture, B: form as the plantation was carried out. Axis 1 represents $46.6 \%$ of the total variability and axis 2 represents $29.1 \%$.

cultivo de Tabebuia avellanedae, a colonização micorrízica decresceu em função da redução na luminosidade, o que pode ter sido ocasionado pelo alto custo da planta em manter a associação simbiótica com o FMA.Cordeiro et al. (2005) observaram que a colonização por FMA do milho foi maior em áreas onde uma gramínea, como a braquiária, havia sido plantada anteriormente.

Nas áreas 3 e 6, em que se utilizou o cultivo mínimo para a reforma dos plantios de eucalipto (Tabela 3), não foi possível observar altos valores de colonização micorrízica. Atualmente, o que se preconiza é a produção florestal com maior sustentabilidade, que pode ser adquirida com o emprego do cultivo mínimo, onde a dinâmica dos microrganismos no solo pode representar maior diversidade biológica e fisiológica do solo porque possuem um alto poder de decomposição e ciclagem dos nutrientes. A manutenção dos resíduos na superfície condiciona a formação do “mulching”, agregando muitos benefícios ao sistema de manejo do solo, iniciando com a manutenção da água no sistema e seguindo com a proliferação da associação micorrízica (SANCHES et al., 1995).

Não houve relação entre a colonização micorrízica e o número de esporos na área que recebeu o cultivo mínimo, nem altas taxas de colonização por FMA. O número de esporos porém o maior, provavelmente pode ter sido influenciado pelo pouco revolvimento realizado no solo. Esse fato pode ser positivo se for considerado apenas o número de esporos, e negativo, pois a forma que os fungos têm de reagir quando algo não está em desequilíbrio em seu hábitat é produzir esporos que garantirão a perpetuação de sua espécie.

É difícil comparar a colonização micorrízica de diferentes plantas, devido à compatibilidade diferenciada com as espécies de fungos micorrízicos do solo e à variação nas características genéticas das plantas, que determinam sua dependência das micorrizas. Os FECM são os mais específicos quanto à colonização, nas áreas estudadas, predominando os gêneros Pisolithus e Scleroderma, enquanto os FMA predominantes foram dos gêneros Acaulospora sp. e Glomus sp. 
Tabela 3 - Descrição dos tipos de manejo utilizados nos plantios de eucalipto na região leste de Minas Gerais. Table 3 - Description of management types used in plantings of eucalyptus in eastern Minas Gerais.

\begin{tabular}{ll}
\hline \multicolumn{1}{c}{ Manejo } & \multicolumn{1}{c}{ Descrição } \\
\hline Queimada/Regeneração (QRg) & $\begin{array}{l}\text { Após a colheita, os restos culturais foram queimados e as plantas deixadas para } \\
\text { uma regeneração natural, recebendo calagem e adubação. } \\
\text { Os restos culturais foram queimados, a área foi destocada, o solo recebeu calagem e } \\
\text { adubação antes do plantio de novas mudas. } \\
\text { Queimada/Reflorestamento (QRf) } \\
\text { Queimada/Plantio(QP) } \\
\text { sementes, nunca foi reformada. }\end{array}$ \\
$\begin{array}{ll}\text { Cultivo Mínimo/ Reflorestamento } \\
\text { (CmRf) }\end{array}$ & $\begin{array}{l}\text { Revolvimento mínimo do solo e manutenção dos resíduos vegetais. } \\
\text { ciclos de plantio e corte. }\end{array}$ \\
Cultivo Mínimo/Plantio(CmP) & Semelhante ao descrito no manejo CmRf, porém essa área estava no seu primeiro plantio.
\end{tabular}

Os fungos micorrízicos em plantios de eucalipto são importantíssimos, uma vez que auxiliam na absorção de água e nutrientes nos solos, por meio de suas hifas que têm alta capacidade de proliferação e aumentam a zona de absorção, melhorando assim o desenvolvimento das plantas (SMITH ; READ, 1997). A formação da associação micorrízica é dependente de fatores ambientais, da fisiologia do hospedeiro, do inóculo do solo e da população dos outros microrganismos (PERRY et al., 1987), que podem influenciar o desenvolvimento e o estabelecimento da simbiose com interações positivas (MEYER; LINDERMAN, 1986), negativas (MCALLISTER et al., 1995), ou neutras (EDWARDS et al., 1998).

Em todas as épocas, não foram observados arbúsculos nas amostras de sistema radicular coletadas, apenas vesículas e micélios em abundância, o que corrobora a caracterização morfológica dos esporos realizada, pois espécies da família Gigasporaceae, a exemplo de Gigaspora e Scutelospora, não formam vesículas (SCHÜBLER et al., 2001).

Os resultados desse estudo mostram que as interferências no solo provocadas pelos diferentes tipos de manejo e pela idade das plantas promoveram diferenças nas taxas de colonização das raízes e no número de esporos de FMA. Isso indica que o estabelecimento da simbiose micorrízica é uma estratégia dessas plantas para superar os estresses bióticos e abióticos que ocorrem no solo.

\section{CONCLUSÕES}

A idade das plantas e o tipo de manejo utilizado na implantação da cultura do Eucalyptus grandis e Eucalyptus urophylla afetaram a colonização das raízes de eucalipto por fungos micorrízicos arbusculares e ectomicorrízicos. Não foi possível observar, nas condições avaliadas deste trabalho, a sucessão micorrízica FMA-FECM.

\section{AGRADECIMENTOS}

À CAPES, ao CNPq e à FAPEMIG, pelo apoio financeiro. À empresa CENIBRA Celulose Nipo-Brasileira S.A., MG, pelo suporte técnico e financeiro para a realização das coletas. Aos funcionários da Cenibra, Fernando Leite e Gilson Gaudereto, pelo apoio técnico durante as coletas.

\section{REFERÊNCIAS}

BELLEI, M. M. et al. Mycorrhizal succession in young Eucalyptus viminalis plantations in Santa Catarina (Southern Brazil). Forest Ecology Management., v.54, n.1, p.205-213, 1992.

BRAGA, F. et al. Exigências nutricionais de quatro espécies. Revista Árvore, v.19, n.1, p.18-31, 1995.

\section{BRUNDRETT, M. C. et al. Working with mycorrhizas in forest and agriculture. Camberra: Pirie, 1996. 374 p.}

CAPRONI, A. L. et al. Fungos micorrízicos arbusculares em estéril revegetado com Acacia mangium, após mineração de bauxita. Revista Árvore, v.29, n.3, p.373-381, 2005.

COELHO, F. C. et al. Caracterização e incidência de fungos micorrízicos em povoamentos de Eucalyptus camaldulensis dehnh., nos municípios de Paraopeba, Bocaiuva e João Pinheiro, Minas Gerais. Revista Árvore, v.21, n.3, p.393-404, 1997.

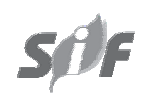

Revista Árvore, Viçosa-MG, v.35, n.5, p.965-974, 2011 
CORDEIRO, M. A. S. et al. Colonização e densidade de esporos de fungos micorrízicos em dois solos do cerrado sob diferentes sistemas de manejo. Pesquisa

Agropecuária Tropical, v.35, n.3, p.147153, 2005.

GERDEMANN, J. W.; NICOLSON, T. H. Spores of mycorrhizal endogone species extracted from soil by wet sieving and decanting. Transaction Britannic Mycological Society, v.46, n. 1, p.235-244, 1963.

GIOVANNETTI, M.; MOSSE, B. An evaluation of techniques for measuring vesicular arbuscular mycorrhizal infection in roots. New

Phytologist, v.84, n. 3, p.489-500, 1980.

KOSKE, R.; GEMMA, J. N. A modified procedure for staining roots to detect VA mycorrhizas.

Mycological Research, v.92, n. 4, p.486-505, 1989.

MARCHNER, H.; DELL, B. Nutrient uptake in mycorrhizal symbiosis. Plant Soil, v.159, n.1, p.89-102, 1994.

MCCUNE, B.; MEFFORD, M. J. PC-ORD Multivariate analysis of ecological data, Version 4.5, MJM Softtware Design. Gleneden Beach, Oregon, 1999. 237p.

MORATELLI, E. M. et. al. Efeito da disponibilidade de água e de luz na colonização micorrízica e no crescimento de Tabebuia avellanedae Lorentz ex Griseb. (BIGNONIACEAE). Revista Árvore, v.31, n.3, p.555-566, 2007.

MOREIRA, M. et al. Spore density and root colonization by arbuscular mycorrhizal fungi in preserved or disturbed Araucaria angustifolia (Bert.) O. Ktze. ecosystems. Scientia Agricola, v.63, n.4, p.380-385, 2006.
SANCHES, O. A. et al. Evolução do cultivo mínimo em reflorestamento na cia. Suzano de papel e celulose. In: SEMINÁRIO SOBRE CULTIVO MÍNIMO DO SOLO EM

FLORESTAS, 1., 1995, Curitiba. Anais... Piracicaba: CNP/Floresta, IPEF, UNESP, SIF, FUPEF, 1995. p.140-147.

SANTOS, V. L. et al. Vesicular-arbuscular-/ ectomycorrhiza succession in seedlings of Eucalyptus spp. Journal Brazilian Microbiology, v.32, n.1, p.81-86, 2001.

SCHÜBLER, A.; SCHWARZOTT, D.; WALKER, C. A. New fungal phylum, the Glomeromycota: phylogeny and evolution. Mycological Research, v.105, n.12, p.1413-1421, 2001.

SILVA, E. A. et al. Efeitos da rochagem e de resíduos orgânicos sobre aspectos químicos e microbiológicos de um subsolo exposto e sobre o crescimento de Astronium fraxinifolium Schott. Revista Árvore, v.32, n.2, p.323-333, 2008.

SMITH, S. E.; READ, D. J. Mycorrhizal symbiosis. London: Academic Press, 1997. 605p.

SOCIEDADE BRASILEIRADE SILVICULTURA. Disponível em: < ttp://www.sbs.org.br/ estatisticas.htm>. Acesso em 02 março de 2009.

SPECHT, R. L. The influence of soil on the evolution of eucalypts. In: ATTIWELL, P.M.; ADAMS, M. A. (Ed.) Nutrition of Eucalyptus. Camberra: 1996. 60p.

VIANELLO, R. L.; ALVES, A. R.

Meteorologia básica e aplicações. Viçosa MG: Universidade Federal de Viçosa, 1991. 449p.

YINGLONG, C. et al. Mycorrhizal succession and inoculant efficiency of dual inoculation on Eucalyptus urophylla. Foresty Studies, v.1, n.1,p.16-21, 1999. 